\title{
Pottery Invention and Innovation in East Asia and the Near East
}

\author{
Kevin Gibbs
}

\begin{abstract}
The invention of ceramic objects made from fire-hardened clay represents an important and early step in the development of pyrotechnology. This paper examines pottery invention and innovation by hunter-gatherers in East Asia and by farmers in the Near East to examine how prehistoric communities in different socio-economic systems came to rely heavily on fired-clay containers. Drawing on advances in archaeological science, it examines from a comparative perspective early pottery's broader entanglements related to technology and use and argues that early pottery production by farmers in the Near East can be viewed as a process of innovation in a longer tradition of container technology, while the first hunter-gatherer pottery production in East Asia provides a better case for independent invention.
\end{abstract}

\section{Introduction}

The invention of ceramic objects made from firehardened clay represents an important and early step in the development of pyrotechnology. Fired clay figurines have been found at Gravettian/Pavlovian sites such as Dolni Věstonice in the Czech Republic, as early as c. 31,000-27,000 cal вр (Vandiver et al. 1989). By around $20,000-18,000$ cal вР there is evidence for ceramic containers-pottery-in southern China. Pottery technology subsequently appears at Late Pleistocene and Early Holocene sites in a wide range of environmental zones and eventually becomes one of the most abundant artefact types at prehistoric sites across the Old World (Barnett \& Hoopes 1995; Gibbs \& Jordan 2013; Jordan \& Zvelebil 2009).

Despite the widespread occurrence of pottery in the archaeological record, there is relatively little consensus about how and why it was invented. Its overall success as a technology may have derived from both its functional benefits in cooking and storage and, in some contexts, its value as a prestige or symbolic object. But in the earliest stages of pottery production it is typically rare, and its long-term impact on diet, health, trade, social organization and ritual behaviour may not have been a consideration of the people who first made and used it. Understanding the reasons for the invention of pottery, then, requires looking not just at its later impacts, but also at the broader technological, economic and social contexts of its invention and subsequent innovation. Adopting a broad perspective on the invention of pottery can benefit from a multidisciplinary approach that considers developments in both archaeological science and archaeological theory. One potentially productive starting point is to consider the range of interconnections that pottery had with other things, processes and people.

As Late Pleistocene and Early Holocene pottery occurs in a range of Old World contexts (Gibbs \& Jordan 2013), it is not surprising that the kinds of connections that pottery exhibited in the past varied between regions. This paper compares the contexts of pottery invention and innovation in two key areas where we see evidence for early pottery production: in East Asia, where pottery was first invented by mobile hunter-gatherers, and in the Near East, where the earliest pots were made and used by sedentary farmers (Figs. $1 \& 2$ ). In this paper, I 

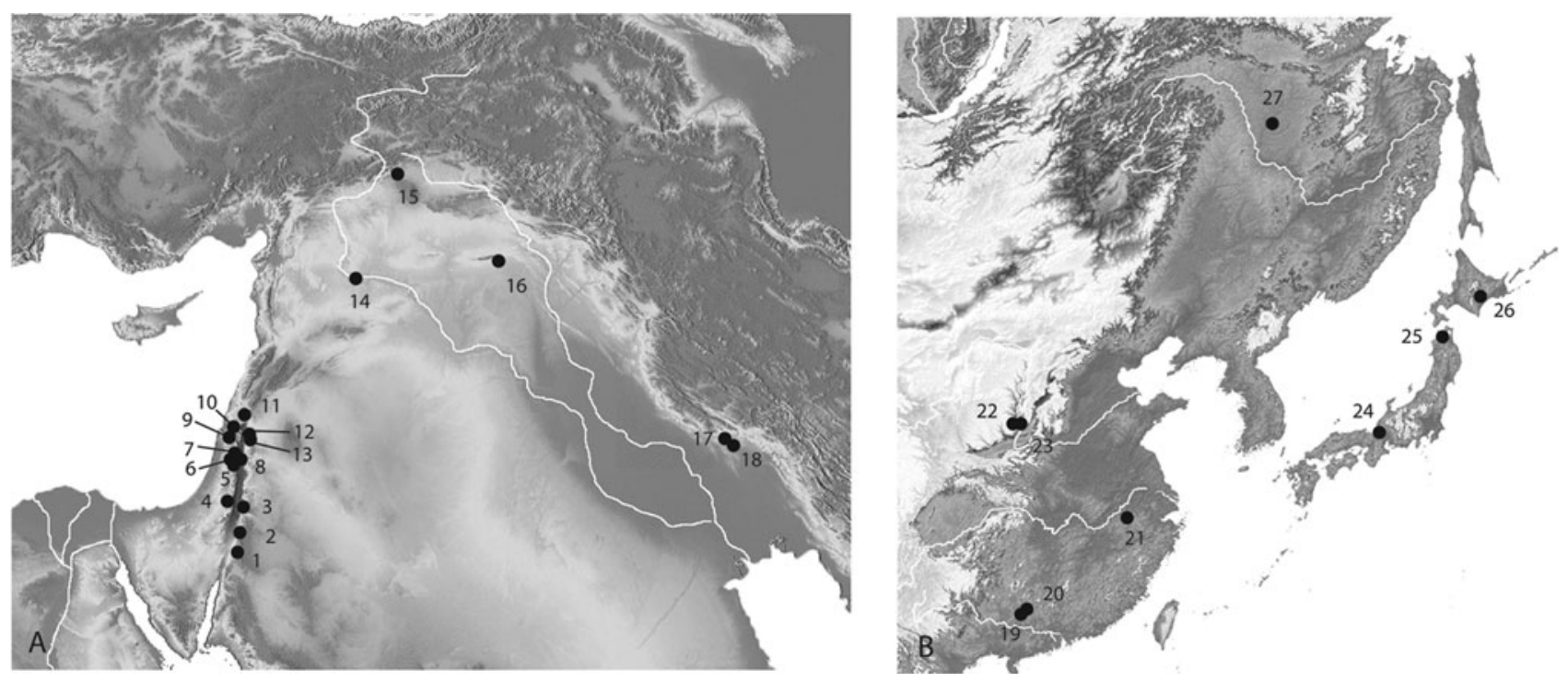

Figure 1. Map of the Near East (A) and East Asia (B), showing sites mentioned in the text. 1. Beidha; 2. WF16; 3. Dhra'; 4. Nahal Hemar; 5. Jericho; 6. Salibiya I; 7. Netiv Hagdud; 8. Gilgal; 9. Kfar Hahoresh; 10. Hayonim; 11. 'Ain Mallaha; 12. WQ117; 13. Al-Basatîn and Tabaqat al-Bûma; 14. Abu Hureyra; 15. Çayönü; 16. Yarim Tepe I; 17. Chageh Sefid; 18. Ali Kosh; 19. Zengpiyan and Dayan; 20. Yuchanyan Cave; 21. Xianrendong; 22. Longwangchan; 23. Shizitan; 24. Torihama; 25. Odai Yamamoto 1; 26. Taisho 3; 27. Gromatukha.
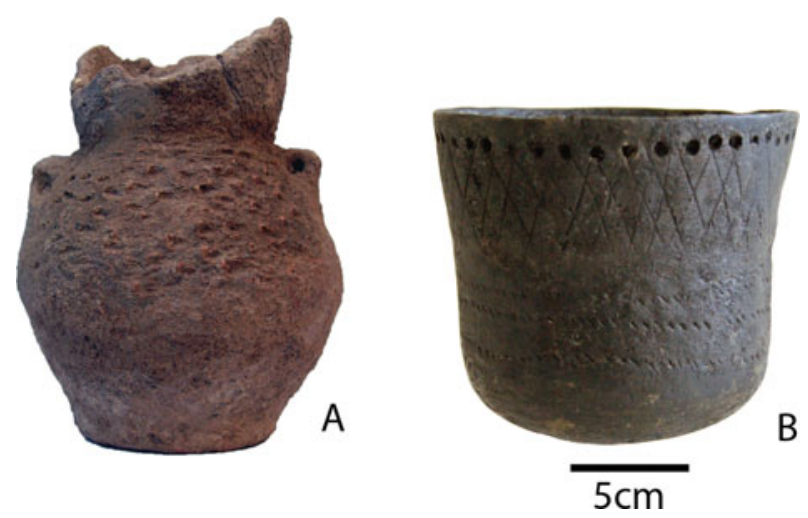

Figure 2. (Colour online) (A) Late Neolithic pottery from Tabaqat al-Bûma, northern Jordan; (B) Incipient Jomon pottery from Torihama, western Honshu, Japan. (Photographs: K. Gibbs.)

argue that early pottery in the Near East was connected to a wide range of other technological developments, including other pyrotechnologies (e.g. plaster production, ceramic figurine production), and may have had a fairly wide range of uses. In contrast, early pottery in East Asia seems to exhibit fewer connections with other technological traditions; and available evidence, though limited, indicates that pottery may have been fairly restricted in function. Given these differences, in the Near East pottery is best viewed as a stage of innovation in the devel- opment of wider systems of container technologies and pyrotechnologies. In East Asia, pottery was less dependent on other pre-existing developments and should be viewed as a case of more independent invention.

\section{Invention and innovation}

Renfrew $(1984,391)$ provides a straightforward definition of invention: 'the discovery or achievement by an individual of a new process or form, whether deliberately or by chance'. In terms of new technologies, invention is often seen as linking a need with a means of achieving that need (Arthur 2009, 109). The second part of Renfrew's definition-'whether deliberately or by chance'-highlights the fact that the process of invention can follow two general patterns. Invention can start with a need, followed by the search for a way of achieving that need, or it can start with the discovery of a new effect or phenomenon, followed by the search for a way of putting that effect or phenomenon to use (Arthur 2009, 110). It is possible that in some regions the invention of pottery corresponded with a newly developed need, perhaps the introduction of a new potential food source that could be better exploited using durable, water-tight containers. Or it could have originated from the other end of the chain, with the observance that baked clay creates a hard 
and durable substance. Invention is commonly distinguished from innovation, with the latter seen as the development or expansion of a new invention. For example, Renfrew $(1984,391)$ defines innovation as the widespread adoption of a new process or form, while Fitzhugh (2001) sees it as the process of testing and putting an invention into practice.

In fact, the distinction between invention and innovation may not always be clear cut. The path from need to invention to innovation (or invention to need to innovation) is usually not strictly linear. Instead, there are feedback paths and recursive structures that may require the discovery and implementation of further solutions (Arthur 2009, 110; Kline \& Rosenberg 1986). In other words, innovation may require further invention. It is also worth stressing that technological inventions rarely, if ever, occur in isolation. Basalla (1988) shows how seemingly revolutionary technological inventions can actually be the result of continuous evolution from pre-existing technologies. Furthermore, Arthur (2009) points out that technologies are usually comprised of multiple components, and inventions may actually be the recombination of preexisting components that were each invented earlier. It can be difficult, then, to identify a technology as either a new invention or the development of an existing technology.

When discussing pottery as a new technology, it is important to think about the needs that it fulfilled and also the pre-existing technologies or technological components that directly contributed to its development. However, it is also important to think about the broader technological and social frameworks, as these can have a significant impact on the path from invention to innovation. A technological invention may involve linking a need with a means of achieving that need (Arthur 2009), but not all potentially useful or valid inventions will be adopted. Indeed, as discussed by Lemonnier (1992), seemingly inefficient technologies are sometimes adopted or retained, despite knowledge of more effective alternatives. In Hodder's (2012) terms, the acceptance of a new technology is a matter of 'fittingness'. An invention is put into widespread practice- becomes an innovationnot solely because it may increase survival or reproductive success, but rather because it works within the 'overall entanglement of humans and things' (Hodder 2011, 165).

\section{Entanglement}

Archaeologists have used a number of analytical approaches to examine the connections that objects have with people, other objects, and processes. For example, chaîne opératoire and behavioural chain ap- proaches have been used to outline sequences of technological production and the interaction of raw materials, tools and people required to make things and complete tasks (e.g. Lemonnier 1993; Schiffer 1987). Network approaches, including Actor Network Theory, have emphasized the importance of understanding not only the relationships between individuals and groups of people in the past, but also the relationships between people and objects (e.g. Knappett 2011). Within this broader perspective on the importance of objects in the past, the idea of entanglement is useful, as it highlights the fact that the interconnections between people and things were often rather complicated, contingent and intersecting, and extending in multiple directions (Hodder 2012).

Hodder $(2011 ; 2012)$ highlights another important element of entanglement: webs of connections can act as traps that are difficult to get out of. This is due to the various types of dependencies that give rise to human-thing entanglements. Humans rely heavily on things for subsistence, exchange, maintaining social relations, communicating status and meanings, and a wide range of other purposes. But Hodder (2012) also emphasizes that things depend on people, as well as other things. Things continually break down and decay, requiring humans to repair and replace them. In the case of early pottery, archaeologists have documented examples of repair, and in other cases pots may have been thought of as largely disposable, to be discarded and replaced on a regular basis (Gibbs 2012). The entanglements created by these different types of dependence can influence and limit the direction of future innovations. As people become invested in doing and making things in certain ways, it becomes increasingly difficult to adopt new technologies and behaviours. People become trapped into working within the technological webs that have already been created, choosing to adapt and develop what already exists rather than abandoning them for new ways of doing things.

Entanglement, therefore, has a temporal dimension to it and can contribute to explaining not only why pottery was first produced by Late Pleistocene and Early Holocene communities, but also how it developed over time, eventually becoming a dominant pyrotechnological innovation. A detailed outline of these temporal developments is beyond the scope of this paper, and in the following sections I limit discussion largely to those connections that were important at the start of pottery production in East Asia and the Near East. However, it should be remembered that the reasons for early experiments with pottery production might have been rather different from the reasons that 
EAST ASIA

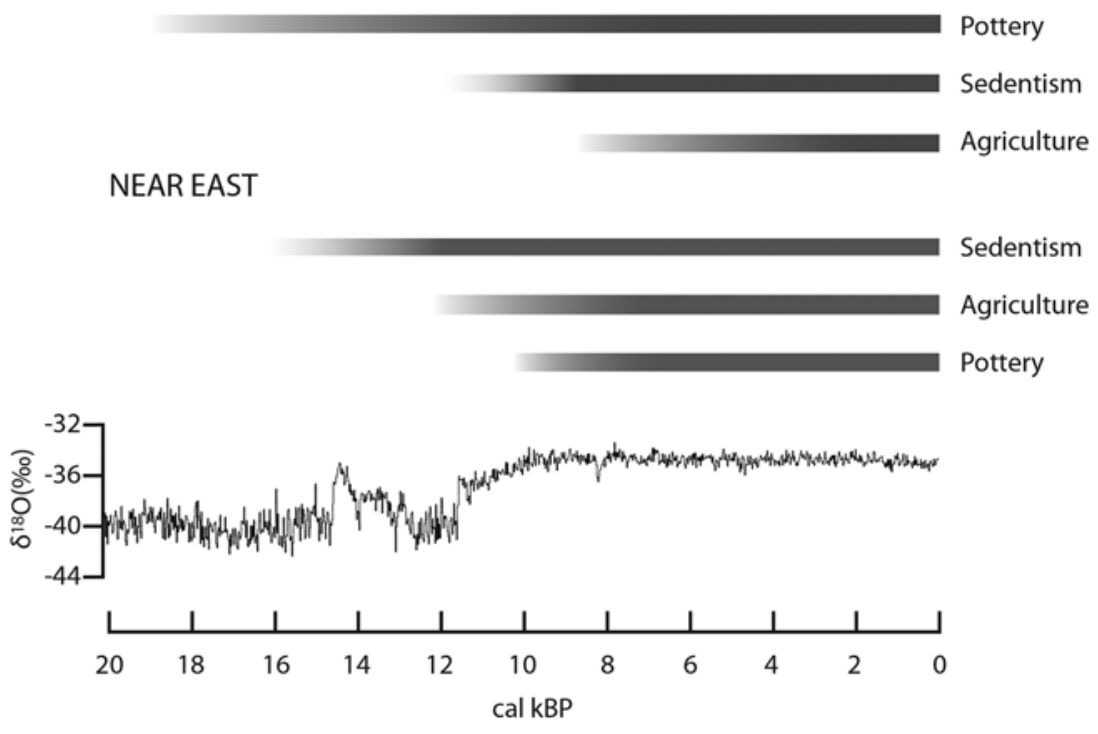

Figure 3. Approximate start dates for developments commonly associated with the transistion to the Neolithic. Note the different order of these developments in East Asia and the Near East. Temperature curve is from the GISP2 core (Johnsen et al. 2001).

led to its widespread adoption and dispersal across the Old World.

\section{The origins of pottery}

There is a long history of associating the invention of pottery with sedentary farmers (e.g. Lubbock 1865). The work of Childe (1936), in particular, was important in promoting the correlation of pottery, agriculture and sedentism and the spread of these developments as a 'Neolithic package' from the Near East across Europe. In this traditional view, the connections that pottery had with other things, substances and processes were closely tied with the factors and conditions that led to the shift to farming and sedentary village life. However, in the Near East it is now clear that pottery, farming and sedentism developed independently and at different times (Fig. 3). There is evidence for sedentary sites during the Early Natufian period (15,000-13,000 cal BP: Bar-Yosef \& BelferCohen 1989). The cultivation of wild plants probably started in the Late Natufian (13,000-11,700 cal BP) or the first part of the Neolithic (Pre-Pottery Neolithic A: 11,700-10,500 cal вр), with domesticated plants and animals becoming an important part of the economy by the Pre-Pottery Neolithic B (10,500-9000 cal вP: Zeder 2011). During the PPNB we also start to see evidence for the limited manufacture of pottery (Biton et al. 2014; Smith 1978), but it does not become widespread until after $9000 \mathrm{cal}$ BP, centuries after the first appearance of sedentary farming villages (Moore 1995).

Likewise in East Asia, the origins of pottery, sedentism and agriculture did not develop simultaneously and there was likely a high degree of regional variation. In southern China, pottery dates to 18,000 cal BP or earlier (Boaretto et al. 2009; Wu et al. 2012) and in Japan and the Russian Far East pottery has been dated to around 16,500 cal вр at sites including Odai Yamamoto 1 and Gromatukha (Keally et al. 2004). The people who made and used this early pottery were likely residentially mobile, with sedentary sites not occurring until after the onset of the Holocene (Habu 2004, 248; Liu \& Chen 2012, 70-71; Pearson 2006). The domestication of millet in China may not have occurred until around 8000 to $7500 \mathrm{cal}$ BP and rice about a millennium later (Fuller et al. 2009; Zhao 2011, S301). In Japan rice agriculture was not introduced until $3000 \mathrm{cal}$ BP or later, but there was a long tradition in the archipelago of the cultivation of other species (Crawford 1983).

The invention of pottery, then, was not simply a correlate of the transition to a sedentary farming lifestyle, even in the Near East, and the connections it had with other technologies should be investigated in more detail. In fact, the flexibility of pottery as a craft and the myriad considerations and decisions that a potter may face (van der Leeuw 2008) makes listing the potential connections of pottery a daunting if not impossible task. Moreover, thinking of these 
connections as entangled, and thus overlapping and contingent, makes it difficult to classify them into discrete categories. For example, early Near Eastern clay pots can be thought of as technologically connected to plaster 'white ware' vessels (see below) by raw materials, production sequence, colour, ritual potential, portability, and their capacity to serve as containers. Nevertheless, in order to highlight potential differences between the Near East and East Asia, in the remainder of this paper I wish briefly to highlight some connections related specifically to (a) the technological milieu in which pots were first made and (b) the needs that pottery may have served.

\section{Firing early pottery}

But first it is worth making a few comments on the more specific pyrotechnological aspects of early pottery production in these regions. The invention of pottery required the combination of heat and clay to make a durable container, but this can be achieved in a number of ways. Potters have a range of options for the type of firing structure, the fuel used, the firing schedule and scale (Livingstone Smith 2001). Simple firing structures may have existed at the very beginning of ceramic pyrotechnology. Vandiver et al. (1989) employed differential thermal analysis aided by $\mathrm{x}$-ray diffraction (XRD) and scanning electron microscopy to determine that the Palaeolithic figurines from Dolni Věstonice were fired at a range of $500-800^{\circ} \mathrm{C}$. Two structures at the site were identified as simple kilns that were used to achieve this temperature range.

In East Asia there are no comparable kilns reported with the earliest pottery. Pots may have been fired in more ephemeral bonfires or even multipurpose domestic hearths, or could have been fired 'off site', away from excavated deposits. According to $\mathrm{Lu}(2011,18)$ some early pots from Dayan and Zengpiyan in southern China were fired at approximately $600-700^{\circ} \mathrm{C}$ but the earliest pots from Zengpiyan may have been fired below $250^{\circ} \mathrm{C}$, which would not require a complex firing structure. Zhushchikhovskaya (2005) states that the earliest pottery in the Russian Far East was fired at $400-600^{\circ} \mathrm{C}$. Unfortunately, because different types of firing structures can result in greatly overlapping temperature ranges (Gosselain 1992; Livingstone Smith 2001), it is difficult, if not impossible, to infer the type of structure (e.g. bonfire, pit, kiln) based on firing temperature alone. In China, kilns have been discovered at Neolithic Peiligang and Cishan culture sites (Zhu 2013, 177), but these postdate the region's earliest pottery by millennia.

In the Near East, excavations at the site of Yarim Tepe I uncovered the remains of a double-chamber updraught pottery kiln dating to around 8000 years ago (Hansen Streily 2000, 71). Firing structures associated with earlier pottery have not been positively identified. The tradition of lime plaster production in the Levant (see below) suggests that the first potters in the region may have been familiar with kiln construction, although it is possible that the high temperatures required to make plaster were achieved in simple pit kilns (Goren \& Goring-Morris 2009; Gourdin \& Kingery 1975).

\section{Technological entanglements}

As noted above, Basalla (1988) and Arthur (2009) point out the importance of understanding the technological precursors and constituent components of a new technology. For pottery, these include, among other things: (1) earlier types of containers; (2) technologies that share common raw materials, especially the manipulation of clay; and (3) other pyrotechnologies.

\section{Containers}

In the Near East, there are rare occurrences of baskets, textile bags and wooden bowls dating to the Pre-Pottery Neolithic. At Gilgal, for examples, excavators recovered fragments of PPNA basketry (Schick 2010) and excavations at Nahal Hemar Cave produced fragments of PPNB basketry, a net bag and cordage containers covered in bitumen (Schick 1988). A wooden box was found at the PPNB site of Beidha (Mortensen 1988). Groundstone bowls are better preserved, with examples as early as the Early Epipalaeolithic, c. 20,000 cal вр (Maher et al. 2012; Wright 1991). Containers made from unfired clay and plaster are discussed below.

In East Asia, there is little evidence for containers that pre-date the first pottery. There are Palaeolithic groundstone implements from China, for example at Shizitan Locality 14 (c. 23,000-19,500 years ago), but these flat slabs would not function as containers and were likely used to grind plant materials (Liu et al. 2013). Some early pottery from the Russian Far East appears to have been made in basketry or cordage moulds (Zhushchikhovskaya 2005), suggesting the prior existence of containers made from these materials.

\section{Shared raw materials}

In the Near East, the manipulation of clay to produce objects pre-dates the production of pottery (Schmandt-Besserat 1977). For example, clay was used to make unfired mud bricks for architectural purposes at PPNA sites, including Jericho and Netiv Hagdud (Bar-Yosef \& Gopher 1997; Kenyon 1981). At other PPNA sites, people constructed pisé structures, for 

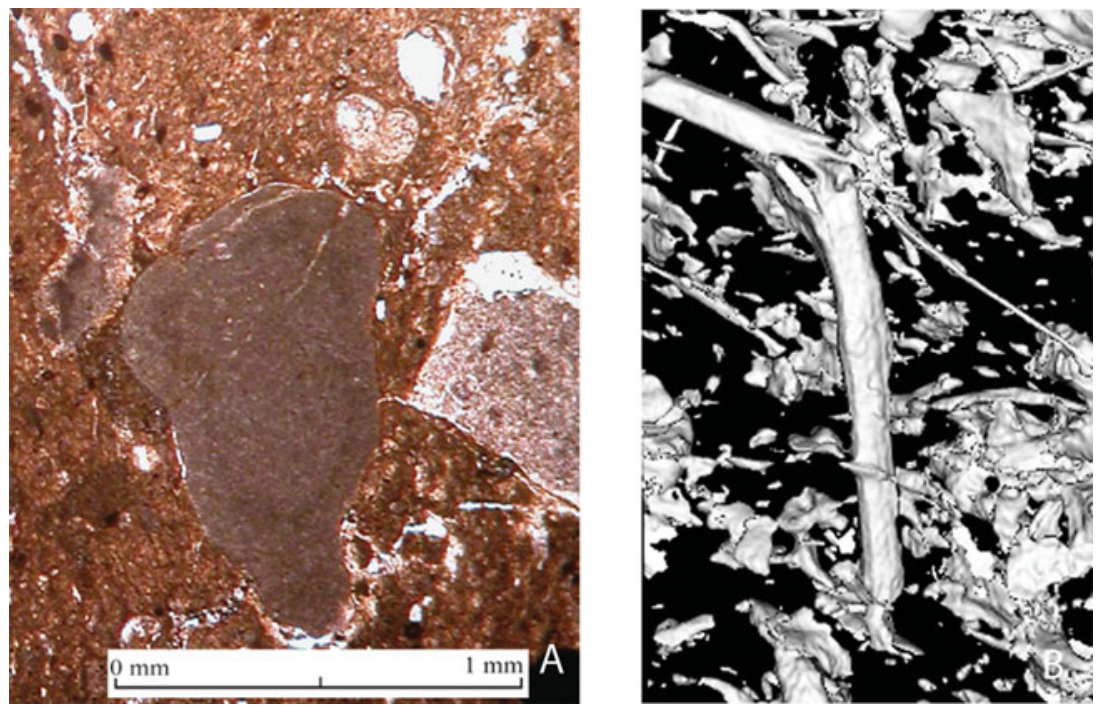

Figure 4. (Colour online) Archaeometric techniques can shed light on the components of early pottery. (A) Thin-section petrography shows a limestone inclusion in a Late Neolithic pot from Tabaqat al-Bûma, northern Jordan. Limestone was also used to make groundstone implements at the site. (B) Voids in a pot from the Late Neolithic site of al-Basatin, northern Jordan, as visualized by high-resolution computed tomography (micro CT), showing a vegetal inclusion. (Images: K. Gibbs.)

example at Dhra' and WF16 (Finlayson et al. 2011; Kuijt \& Finlayson 2009). Clay was also used to make portable objects. For example, an unfired clay figurine was discovered at the Natufian site of Hayonim Terrace and several clay lumps were recovered from the Natufian site of Salibiya I (Ben-Michael 2012; Crabtree et al. 1991). Clay figurines became more common during the Pre-Pottery Neolithic and clay was used to make geometric objects or tokens during the PPNB, which perhaps had some accounting function (Schmandt-Besserat 1992). During the Pre-Pottery Neolithic, clay was also sometimes used to make small, unfired containers, for example at Çayönü and $\mathrm{Abu}$ Hureyra (Moore 1995; Özdoğan 2009).

In East Asia, there is little evidence for the use of clay prior to the invention of pottery. $\mathrm{Lu}$ (2011) reports two pieces of fired clay from Phase II at the site of Dayan in southern China, but these may not pre-date the earliest ceramic vessels in the region. Liu and Chen $(2012,58)$ suggest that 'hoe-shaped' implements from Yuchanyan Cave in southern China may have been used for digging soil, but it is impossible to say if these had any connection with procuring the raw materials used for pottery making.

Apart from clay, the other major component of pottery is the inclusions, some of which may be intentionally added as temper (Fig. 4). In the Near East, some early pots were tempered with calcite and basalt (Le Mière 2009). These are materials associated with other technologies, including the construction of basalt groundstone objects and plaster objects (see below). Other vessels were tempered with vegetal material (Le Mière 2009), as were some Pre-Pottery Neolithic mud bricks.

Pottery temper suggests some possible connections with other technologies in East Asia as well. Early pottery in China was sometimes tempered with quartz or quartzite (Zhang 2002), materials that were also used in stone tool manufacture, for example at the Longwangchan site in north China (Liu \& Chen 2012, 47-50). In other cases pottery may have been tempered with shell (Zhang 2002), a material that may have been used to produce ornaments, for example at Yuchanyan Cave and Longwangchan (Bar-Yosef \& Wang 2012; Liu \& Chen 2012, 49).

\section{Pre-Pottery pyrotechnology}

In the Near East, two examples of pre-pottery pyrotechnologies stand out. First, some of the noncontainer clay objects-figurines and tokens-that date to the Natufian and Pre-Pottery Neolithic show evidence of exposure to fire. In some cases this exposure might have been accidental or post-depositional. In other cases, however, it is likely that clay was being intentionally fired to make durable objects, demonstrating that the knowledge of clay-based ceramic technology pre-dates the production of fired clay vessels in the region. Second, in the Near East there was a development of plaster production extending back to the Late Epipalaeolithic (i.e. Natufian). The 
production of lime plaster involves burning chunks of limestone at temperatures of $800-900^{\circ} \mathrm{C}$. This produces a powdery substance (quicklime) that is slaked with water to create a putty that can be moulded or spread onto architectural surfaces. As carbon dioxide is reabsorbed into the lime putty it re-establishes its original chemical composition, resulting in a hard and durable plaster. Excavations at Hayonim Cave produced evidence for a possible Natufian lime-burning structure and at the Natufian site of 'Ain Mallaha excavators encountered evidence for plastered pits and a plaster bench (Kingery et al. 1988; Perrot 1960). During the Pre-Pottery Neolithic, production of plaster intensified and it was used for a variety of purposes, including floor surfacing and plastering skulls, as well as the production of portable containers, referred to as white ware or vaisselles blanches.

The use of fire to transform the chemical or physical properties of clay or other materials is not attested in East Asia prior to the invention of pottery. Certainly people living in this region would have used fire for warmth, protection and food preparation. Other potential uses of fire in craft production (e.g. heat treatment of lithics) require further investigation.

\section{Entanglements related to need or use}

In addition to understanding the technological connections of early pottery, it is important to investigate the particular needs that ceramic pots may have fulfilled. A number of theories have been proposed to explain why people began to make pottery, with many explanations focussing on the functional benefits of pottery in culinary contexts (Rice 1999). In some cases, the introduction of new foods or an increased reliance on particular food resources may have contributed to the invention of pottery. In contrast, Hayden (1995) highlights the value of pottery in preparing and cooking prestigious foods in contexts of socioeconomic competition.

Various features can be used to assess the function of pottery, including vessel shape and size, raw materials, wear patterns and decoration. These features, however, may not give a clear indication of the specific foods or products that were processed, cooked or stored in a pot. Recent advances in organic residue analysis provide a means to investigate directly the contents of prehistoric pottery. Relevant analytical methods include gas chromatography (GC), gas chromatography-mass spectrometry (GCMS) and gas chromatography-combustion-isotope ration mass spectrometry (GC-c-IRMS: see Pollard et al. 2007).
Near East

As noted above, in the Near East the development of agriculture occurred prior to the first emergence of pottery. As a result, it is difficult to explain the appearance of pottery in terms of new foods associated with the Neolithic, since domesticated animals and plants had been exploited for centuries or millennia without the functional benefits that pottery can provide. Milk is one product that has been implicated in the appearance of pottery in the Near East. As a secondary animal product, dairy may not have been exploited in the very earliest stages of sheep, goat or cattle domestication and could, perhaps, be correlated with later shifts in the development of pottery. Evershed et al. (2008) found evidence for dairy in some early Near Eastern pots. They analysed pottery residues from 23 Late Neolithic and Chalcolithic sites in southeastern Europe, Anatolia, the Levant and Upper Mesopotamia, using GC, GC-MS and GC-c-IRMS, and identified fat residues in a number of samples, with evidence for milk being particularly strong at sites in northwestern Anatolia, where high numbers of cattle bones were also found. Pottery from other sites examined in the study did not indicate similarly high levels of milk use. Instead, evidence indicated the presence of adipose fats from ruminants and pigs.

Gregg (2010) examined early pottery residues from 22 sites in the Near East, including the southern Levant, Upper Mesopotamia and the Zagros. Unlike Evershed et al. (2008), he did not find any clear evidence for milk fats. Instead, residues in the examined samples derive from the adipose fats of ruminant and non-ruminant animals, and in some cases from plant oils. GC-MS and GC-c-IRMS analyses of Late Neolithic pottery from al-Basatîn in northern Jordan (Gibbs et al. 2010; Kadowaki et al. 2008) indicate the use of ruminant or porcine adipose fats (Gregg et al. 2009). At two sites in western Iran, Ali Kosh and Chageh Sefid, Gregg (2010) found markers indicating the presence of bitumen. This may have been applied to the pots as a sealant or the pots could have been used to collect or transport this material, suggesting that not all early pots were used to hold foodstuffs.

\section{East Asia}

Kobayashi $(2004,22)$ suggests that in East Asia, pottery 'enabled a dramatic increase in the range and quantity of food that could be prepared and consumed'. Ikawa-Smith (1976) argues that Jomon pottery may have been particularly useful for processing large quantities of molluscs, but also suggests that pottery could have broadened the resource base by allowing the exploitation of a range of plant and animal resources. Pottery may have been useful for removing 


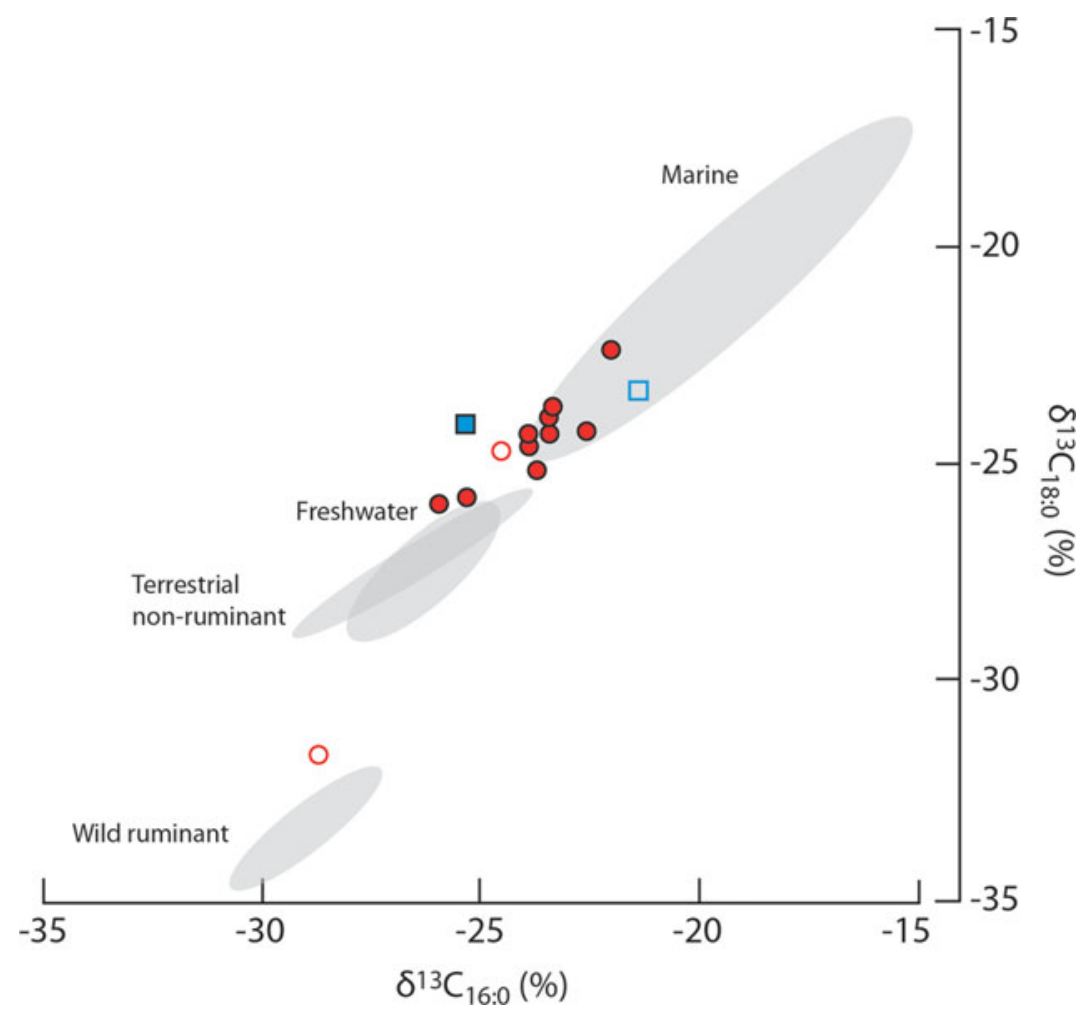

Figure 5. (Colour online) Plot of the $\delta^{13} C$ values of $C_{16: 0}$ and $C_{18: 0}$ fatty acids from charred deposits on Incipient Jomon pottery from Torihama (western Honshu, circles) and Taisho 3 (eastern Hokkaido, squares). Samples that also produced aquatic biomarkers are represented by filled symbols. Ellipses show values of modern reference fats. (Redrawn from Craig et al. 2013.)

the tannins of acorns and other nuts by boiling or soaking, which is a necessary step prior to consumption (Kobayashi 2004, 23). Higham and Lu (1998) state that pottery in China may have been used to cook wild rice, while Elston et al. (2011) suggest that early Chinese pottery was used to process bone grease.

Residue analysis, however, may indicate a more restricted use of early pottery. Craig et al. (2013) analysed Incipient Jomon pottery residues from different regions of Japan, ranging from Hokkaido in the north to Tanegashima of the coast of Kyushu in the south. For most of these samples, the bulk carbon and nitrogen stable isotope values were consistent with hightrophic-level aquatic resources. Analysis of preserved lipids by GC-MS indicated the presence in many samples of biomarkers of degraded aquatic oils, confirming that freshwater and/or marine foods were cooked in these vessels. The good preservation of residues from the Torihama site in western Honshu allowed the measurement of two medium-chain-length saturated fatty acids $\left(\mathrm{C}_{16: 0}\right.$ and $\left.\mathrm{C}_{18: 0}\right)$ using GC-c-IRMS in 12 samples (Fig. 5). Of these, nine samples suggest the presence of marine (rather than freshwater) aquatic resources. Another two had values closer to either freshwater or terrestrial animals, but both of these samples also had aquatic biomarkers. Just one sample from the site closely points to values from modern wild ruminants. Two samples from the Taisho 3 site in Hokkaido also allowed the measurement of $\mathrm{C}_{16: 0}$ and $\mathrm{C}_{18: 0}$ values, and these both point to the processing of marine resources.

\section{Discussion}

Available data from the Near East and East Asia permit a broad comparison of pottery entanglements related to technological context and use. Further research will allow these categories to be expanded and refined. The technological contexts outlined above focus on alternative types of containers, other pyrotechnologies and shared raw materials. However, prehistoric pottery would have had many more connections with other objects, people and processes at all stages of production and use, including raw material selection and processing, forming, decoration, drying, firing, use, recycling and re-use, and discard. Likewise use would not have been restricted to the substances that were processed, cooked or stored in early ceramic 

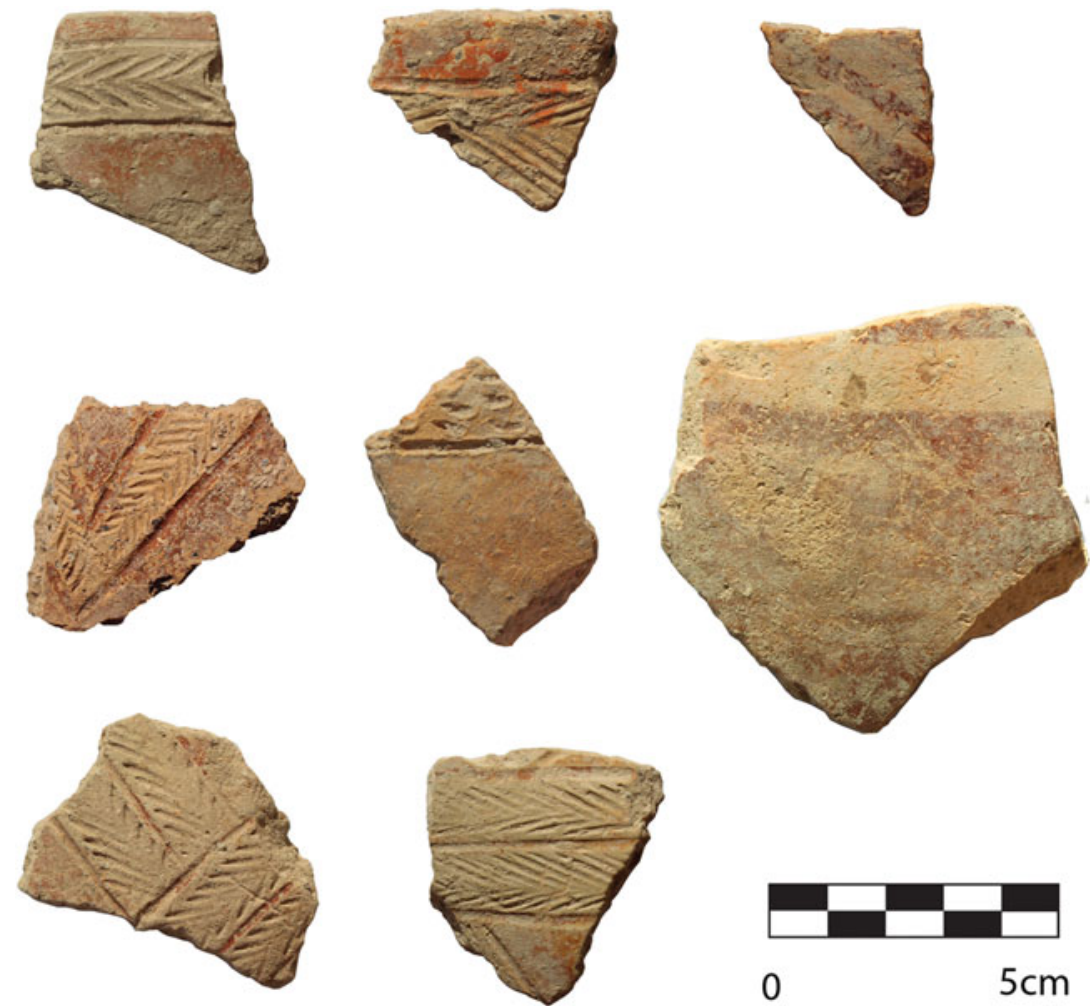

Figure 6. (Colour online) Decorated Late Neolithic pottery from the site of WQ117 in northern Jordan. (Photograph: K. Gibbs.)

pots. Pots may have had other functions, which would have increased their entanglements. In particular, pottery may have had symbolic or social roles in addition to culinary ones and it may be notable that some early pots in both regions were decorated (Fig. 6) (Nieuwenhuyse et al. 2010; Zhang 2002).

It will also be useful for future work to consider the nature and broader significance of the various connections outlined above. For example, what is the significance that in Late Pleistocene China quartz was used to temper pottery and also to make chipped stone tools? Thinking of the production of pottery in relation to other tasks may be a productive way to address such issues and scientific analysis can contribute to this. For example, Biton et al.'s (2014) petrographic study of PPNB pottery from Kfar Hahoresh revealed the presence of faecal spherulites in the fabric of some samples, indicating that the observed vegetal temper derived from the addition of herbivore manure. This may suggest a close spatial connection between the tasks of pottery production and animal husbandry.

Acknowledging the need for further research in both the Near East and East Asia, it is possible to make some comparisons related to early pottery technology and use. Notably, the Near Eastern evidence suggests a wider range of technological entanglements. Pottery first appeared here in an environment that already had several kinds of portable and durable containers, including basketry, textile bags, wooden bowls, white ware and groundstone. Pottery also had technological parallels and precursors in the form of other objects made from clay, such as mud-brick architecture, figurines and tokens. Pyrotechnology, including claybased ceramics and plaster, was well developed in the Near East by the time pottery came about. In contrast, in East Asia early pottery appears to have had fewer technological connections. There is relatively little evidence for alternative types of containers, clay was apparently not used to make other objects, and pyrotechnology seems not to have developed prior to the firing of clay to make portable containers.

The scarcity of studies dedicated to the analysis of organic residues derived from early pottery in both the Near East and East Asia makes it more difficult to comment on connections between pots and the plants and animals that were processed or stored in them. Nevertheless, there is some evidence that pottery in East Asia had a more restricted range of uses. Craig et al. (2013) demonstrate that in Japan early pottery was used primarily for processing or cooking aquatic or marine resources, even though samples derived from a range of environmental contexts. This suggests 
that pottery may have been invented to process particular foods and may not have broadened the overall range of exploited resources. In contrast to East Asia, in the Near East there is more evidence that early pots contained a range of products, including the adipose fats of terrestrial ruminants and pigs, plant oils, milk products and bitumen, and there is some evidence for regional variation (Evershed et al. 2008; Gregg 2010; Gregg et al. 2009).

How should these differences be interpreted? It would be straightforward to say that in East Asia pottery was made by mobile hunter-gatherers who typically have fewer material possessions than sedentary farmers and, as a result, fewer potential material and technological entanglements. But this contributes little to the discussion of early pottery invention or its later innovations. Read and van der Leeuw (2008) suggest that the invention of container technologies was significant, not only for the functional/health benefits and social/symbolic value that containers provide, but also as a stage in the development of human cognition. They argue that containers of all types require a conceptual separation of the surface of an object from its volume, a cognitive development that was not fully established prior to the invention of containers. Container technologies also typically require the separation of different stages of production (e.g. shaping, drying, firing), the concept of combining small particles into larger objects, and a sense that actions are reversible and can be corrected (Read \& van der Leeuw 2008, 1965).

In the Near East, this suite of cognitive developments occurred long before the first appearance of pottery, as represented by earlier types of containers, clay-based technologies and pyrotechnologies such as plaster. Pottery clearly extended from earlier technologies and was comprised of pre-existing components, following the models outlined by Basalla (1988) and Arthur (2009). The many entanglements of early pottery and pre-existing technologies suggest that the emergence of pottery in the Near East is perhaps better viewed as a stage of innovation in the development of a wider system of containers, rather than as an independent invention. This suggestion fits within Knappett et al.'s $(2010,599)$ proposal that the study of fired-clay pots can benefit from acknowledging the 'metaphorical links' that pottery had with a broader container context.

In contrast to the Near East, early pottery in East Asia does not exhibit the same level of entanglement. Surely the first pottery here did not exist in total isolation, but it seems not to have been connected to the same degree to other technologies or used to process as wide a range of resources, although the greater time depth and different level of investigation need to be acknowledged. The lower level of entanglement suggests that the first pottery in East Asia may have been an independent invention, or at least more independent than in the Near East.

It is interesting to note that in both regions there is evidence for a protracted stage of limited pottery production. In East Asia, pottery seems to have been made in limited quantities for millennia until the onset of the Holocene (Keally et al. 2003). In the Near East there is evidence for very limited production of pottery during the Pre-Pottery Neolithic (Biton et al. 2014). Why pottery eventually became the dominant container technology in both regions is a matter of some debate (e.g. Brown 1989; Rice 1999) and cannot be fully explored within the context of the present paper. In the Near East, it is difficult to tie the origin and eventual dominance of pottery to any specific new need. The technological connections and parallels discussed above indicate that the roles of pottery could have been filled by other available containers, limiting pottery's initial impact. One possible avenue for future research is exploring economic processes of increasing returns, which can help explain how a single technological option can achieve dominance out of a range of functionally equivalent possibilities as a result of 'small events' (Arthur 1994, 14) that may be largely invisible in the archaeological record. In East Asia, early pottery had fewer technological entanglements and there were, perhaps, fewer alternative types of containers. As a more independent invention, early pottery in East Asia may have had a greater impact on the lives of the people who made and used it than early pottery in the Near East, in addition to being more significant in terms of the general development of human cognition, as discussed by Read and van der Leeuw (2008). Accounting for the long time lag between pottery's initial invention and its eventual 'take-off' in the Holocene will likely require consideration of a range of factors, including environmental conditions, mobility, social organization, food procurement strategies, and more. But the limited technological and functional entanglements of pottery suggest that its initial 'fittingness' (Hodder 2012) in Late Pleistocene and Early Holocene huntergatherer society was low, and required considerable time to become a fully integrated pyrotechnological tradition (see also Jordan \& Zvelebil 2009).

\section{Summary and conclusion}

In both East Asia and the Near East, pottery, sedentism, agriculture and other developments commonly associated with the Neolithic developed 
independently and at different times (see also Kuzmin 2013). The invention and subsequent innovation of pottery cannot, then, be explained in terms of a welldefined 'Neolithic Package'. Instead, this paper argues that it may be productive to consider the broader contexts of pottery technology, including the many connections or entanglements that early pottery had with other technologies and the different needs or uses that early pottery may have fulfilled. Archaeometric techniques are important for identifying and understanding these entanglements, particularly those related to pottery composition, manufacture and use.

In the Near East, early pottery had a relatively large number of connections with other technologies, including different types of containers, other objects made from the same raw materials, and earlier pyrotechnological traditions. There is some evidence that pottery was used to process, cook or store a range of products. In contrast, in East Asia pottery seems to have had fewer entanglements. There is limited evidence for other kinds of containers or the use of clay, and other pyrotechnologies were not known prior to the first fired-clay pots. One way to approach this difference is to think of the development of pottery in the Near East as an innovation in a broader system of container technologies, while in East Asia pottery can be seen as an invention in the truer sense of the word.

\section{Acknowledgements}

I would like to thank Miljana Radivojević and Ben Roberts for organizing this special journal section and for giving me the opportunity to contribute a paper. I would also like to thank Lisa Maher and two anonymous reviewers for their insightful comments and suggestions. My thoughts on early pottery have benefited from discussions with numerous people, including Peter Jordan, Junzo Uchiyama, Stuart Campbell and Ted Banning.

Kevin Gibbs Archaeological Research Facility University of California, Berkeley Berkeley, CA 94720-1076 USA

Email:k.gibbs@berkeley.edu

\section{References}

Arthur, W.B., 1994. Increasing Returns and Path Dependence in the Economy. Ann Arbor (MI): University of Michigan Press.

Arthur, W.B., 2009. The Nature of Technology: What It Is and How It Evolves. New York (NY): Free Press.
Barnett, W.K. \& J.W. Hoopes (eds.), 1995. The Emergence of Pottery: Technology and Innovation in Ancient Societies. Washington (DC): Smithsonian Institution Press.

Bar-Yosef, O. \& A. Belfer-Cohen, 1989. The origins of sedentism and farming communities in the Levant. Journal of World Prehistory 3, 447-98.

Bar-Yosef, O. \& A. Gopher, 1997. The excavations of Netiv Hagdud: stratigraphy and architectural remains, in An Early Neolithic Village in the Jordan Valley, Part 1: the Archaeology of Netiv Hagdud, eds. O. Bar-Yosef \& A. Gopher. Cambridge (MA): Peabody Museum of Archaeology and Ethnology, 41-69.

Bar-Yosef, O. \& Y.P. Wang, 2012. Paleolithic archaeology in China. Annual Review of Anthropology 41, 319-35.

Basalla, G., 1988. The Evolution of Technology. Cambridge: Cambridge University Press.

Ben-Michael, J., 2012. A female figurine, in Les Fouilles de la Terrasse d'Hayonim (Israël) 1980-1981 et 1985-1989, ed. F.R. Valla. Paris: De Boccard, 393-6.

Biton, R., Y. Goren \& N. Goring-Morris, 2014. Ceramics in the Levantine Pre-Pottery Neolithic B: evidence from Kfar Hahoresh, Israel. Journal of Archaeological Science $41,740-48$.

Boaretto, E., X.H. Wu, J.R. Yuan, et al., 2009. Radiocarbon dating of charcoal and bone collagen associated with early pottery at Yuchanyan Cave, Hunan Province, China. Proceedings of the National Academy of Sciences of the United States of America 106, 9595-600.

Brown, J.A., 1989. The beginnings of pottery as an economic process, in What's New? A Closer Look at the Process of Innovation, eds. S.E. van der Leeuw \& R. Torrence. London: Unwin Hyman, 203-24.

Childe, V.G., 1936. Man Makes Himself. London: Watts \& Co. Crabtree, P.J., D.V. Campana, A. Belfer-Cohen \& D.E. BarYosef, 1991. First results of the excavations at Salibiya I, lower Jordan Valley, in The Natufian Culture in the Levant, eds. O. Bar-Yosef \& F.R. Valla. Ann Arbor (MI): International Monographs in Prehistory.

Craig, O.E., H. Saul, A. Lucquin, et al., 2013. Earliest evidence for the use of pottery. Nature 496, 351-4.

Crawford, G.W., 1983. Paleoethnobotany of the Kameda Peninsula. Ann Arbor (MI): Museum of Anthropology, University of Michigan.

Elston, R.G., D. Guanghui \& Z. Dongju, 2011. Late Pleistocene intensification technologies in Northern China. Quaternary International 242, 401-15.

Evershed, R.P., S. Payne, A.G. Sherratt, et al., 2008. Earliest date for milk use in the Near East and southeastern Europe linked to cattle herding. Nature 455, 528-31.

Finlayson, B., S.J. Mithen, M. Najjar, et al., 2011. Architecture, sedentism, and social complexity at Pre-Pottery Neolithic A WF16, southern Jordan. Proceedings of the National Academy of Sciences 108, 8183-8.

Fitzhugh, B., 2001. Risk and invention in human technological evolution. Journal of Anthropological Archaeology 20, 125-67.

Fuller, D.Q., L. Qin, Y. Zheng, et al., 2009. The domestication process and domestication rate in rice: spikelet bases from the Lower Yangtze. Science 323, 1607-10. 
Gibbs, K., 2012. Not meant to last: mobility and disposable pottery. Documenta Praehistorica 39, 83-93.

Gibbs, K. \& P. Jordan, 2013. Bridging the boreal forest: Siberian archaeology and the emergence of pottery among prehistoric hunter-gatherers of Northern Eurasia. Sibirica 12, 1-38.

Gibbs, K., S. Kadowaki \& E.B. Banning, 2010. Excavations at al-Basatîn, a Late Neolithic and Early Bronze I Site in Wadi Ziqlab, Northern Jordan. Annual of the Department of Antiquites of Jordan 54, 461-76.

Goren, Y. \& A.N. Goring-Morris, 2009. Early pyrotechnology in the Near East: experimental lime-plaster production at the Pre-Pottery Neolilthic B site of Kfar HaHoresh, Israel. Geoarchaeology: an International Journal 23, 779-98.

Gosselain, O.P., 1992. Bonfire of the enquiries. Pottery firing temperatures in archaeology: what for? Journal of Archaeological Science 19, 243-59.

Gourdin, W.H. \& W.D. Kingery, 1975. The beginnings of pyrotechnology: Neolithic and Egyptian lime plaster. Journal of Field Archaeology 2, 133-50.

Gregg, M., 2010. Organic Residue Analysis and the First Uses of Pottery in the Middle East. (BAR International Series 2065.) Oxford: John \& Erica Hedges Ltd.

Gregg, M.W., E.B. Banning, K. Gibbs \& G.F. Slater, 2009. Subsistence practices and pottery use in Neolithic Jordan: molecular and isotopic evidence. Journal of Archaeological Science 36, 937-46.

Habu, J., 2004. Ancient Jomon of Japan. Cambridge: Cambridge University Press.

Hansen Streily, A., 2000. Early pottery kilns in the Middle East. Paléorient 26, 69-81.

Hayden, B., 1995. The emergence of prestige technologies and pottery, in The Emergence of Pottery: Technology and Innovation in Ancient Societies, eds. W.K. Barnett \& J.W. Hoopes. Washington (DC): Smithsonian Institution Press, 257-65.

Higham, C. \& T.L.-D. Lu, 1998. The origins and dispersal of rice cultivation. Antiquity 72, 867-77.

Hodder, I., 2011. Human-thing entanglement: towards an integrated archaeological perspective. Journal of the Royal Anthropological Institute 17, 15477.

Hodder, I., 2012. Entangled: An Archaeology of the Relationships between Humans and Things. Chichester: WileyBlackwell.

Ikawa-Smith, F., 1976. On ceramic technology in East Asia. Current Anthropology 17, 513-15.

Johnsen, S.J., D. Dahl-Jensen, N. Gundestrup, et al., 2001. Oxygen isotope and palaeotemperature records from six Greenland ice-core stations: Camp Century, Dye3, GRIP, GISP2, Renland and NorthGRIP. Journal of Quaternary Science 16, 299-307.

Jordan, P. \& M. Zvelebil (eds.), 2009. Ceramics before Farming: the Dispersal of Pottery among Prehistoric Eurasian Hunter-Gatherers. (University College London Institute of Archaeology Publications.) Walnut Creek (CA): Left Coast Press.
Kadowaki, S., K. Gibbs, A. Allentuck \& E.B. Banning, 2008. Late Neolithic Settlement in Wadi Ziqlab, Jordan: al-Basatîn. Paléorient 34, 105-29.

Keally, C.T., Y. Taniguchi \& Y.V. Kuzmin, 2003. Understanding the beginnings of pottery technology in Japan and neighboring East Asia. The Review of Archaeology 24, 3-14.

Keally, C.T., Y. Taniguchi, Y.V. Kuzmin \& I.Y. Shewkomud, 2004. Chronology of the beginning of pottery manufacture in East Asia. Radiocarbon 46, 345-51.

Kenyon, K.M., 1981. Excavations at Jericho, volume three: The Architecture and Stratigraphy of the Tell. London: British School of Archaeology in Jerusalem.

Kingery, W.D., P.B. Vandiver \& M. Prickett, 1988. The beginnings of pyrotechnology, part II: production and use of lime and gypsum plaster in the Pre-Pottery Neolithic Near East. Journal of Field Archaeology 15, 219-44.

Kline, S.J. \& N. Rosenberg, 1986. An overview of innovation, in The Positive Sum Strategy: Harnessing Technology for Economic Growth, eds. R. Landau \& N. Rosenberg. Washington (DC): National Academy Press, 275305.

Knappett, C., 2011. An Archaeology of Interaction: Network Perspectives on Material Culture and Society. Oxford: Oxford University Press.

Knappett, C., L. Malafouris \& P. Tomkins, 2010. Ceramics (as containers), in The Oxford Handbook of Material Culture Studies, eds. D. Hicks \& M. Beaudry. Oxford: Oxford University Press, 582-606.

Kobayashi, T., 2004. Jomon Reflections: Forager Life and Culture in the Prehistoric Japanese Archipelago. Oxford: Oxbow.

Kuijt, I. \& B. Finlayson, 2009. Evidence for food storage and predomestication granaries 11,000 years ago in the Jordan Valley. Proceedings of the National Academy of Sciences 106, 10,966-70.

Kuzmin, Y.V., 2013. Two trajectories in the Neolithization of Eurasia: pottery versus agriculture (spatiotemporal patterns). Radiocarbon 55, 1304-13.

Le Mière, M., 2009. Early Neolithic pottery from the Near East: the question of temper and its implications, in Méthodes d'approche des premières productions céramiques: étude de cas dans les Balkans et au Levant. Table-ronde de la Maison de l'Archéologie et de l'Ethnologie (Nanterre, France), 28 février 2006. Rahden/Westf.: Verlag Marie Leidorf GmbH, 73-80.

Lemonnier, P., 1992. Elements for an Anthropology of Technology. Ann Arbor (MI): University of Michigan.

Lemonnier, P. (ed.) 1993. Technological Choices: Transformation in Material Cultures Since the Neolithic. London: Routledge.

Liu, L., S. Bestel, J.M. Shi, Y.H. Song \& X.C. Chen, 2013. Paleolithic human exploitation of plant foods during the last glacial maximum in North China. Proceedings of the National Academy of Sciences of the United States of America 110, 5380-85.

Liu, L. \& X. Chen, 2012. The Archaeology of China: from the Late Palaeolithic to the Early Bronze Age. Cambridge: Cambridge University Press. 
Livingstone Smith, A., 2001. Bonfire II: The return of pottery firing temperatures. Journal of Archaeological Science 28, 991-1003.

Lu, T.L.-D., 2011. Early pottery in China. Asian Perspectives $49,1-42$.

Lubbock, J., 1865. Pre-historic Times as Illustrated by Ancient Remains and the Manners and Customs of Modern Savages. London: Williams \& Norgate.

Maher, L.A., T. Richter \& J.T. Stock, 2012. The Pre-Natufian Epipalaeolithic: long-term behavioral trends in the Levant. Evolutionary Anthropology 21, 69-81.

Moore, A.M.T., 1995. The inception of potting in Western Asia and its impact on economy and society, in The Emergence of Pottery: Technology and Innovation in Ancient Societies, eds. W.K. Barnett \& J.W. Hoopes. Washington (DC): Smithsonian Institution Press, 39-53.

Mortensen, P., 1988. A note on a small box with flint blades and arrowheads from Beidha, and its implications, in The Prehistory of Jordan: the State of Research in 1986, eds. A. Garrard \& H.G. Gebel. (BAR International Series 396 (i).) Oxford: British Archaeological Reports, 199207.

Nieuwenhuyse, O.P., P.M.M.G. Akkermans \& J. van der Plicht, 2010. Not so coarse, nor always plain: the earliest pottery of Syria. Antiquity 84, 71-85.

Özdoğan, M., 2009. Earliest use of pottery in Anatolia, in Early Farmers, Late Foragers, and Ceramic Traditions: On the Beginning of Pottery in the Near East and Europe, ed. D. Gheorghiu. Newcastle upon Tyne: Cambridge Scholars Publishing, 22-43.

Pearson, R.J., 2006. Jomon hot spot: increasing sedentism in south-western Japan in the Incipient Jomon $(14,000$ 9250 cal. BC) and Earliest Jomon (9250-5300 cal. BC) periods. World Archaeology 38, 239-58.

Perrot, J., 1960. Excavations at 'Eynan ('Ein Mallaha): preliminary report on the 1959 season. Israel Exploration Journal 10, 14-22.

Pollard, M., C. Batt, B. Stern \& S.M.M. Young, 2007. Analytical Chemistry in Archaeology. Cambridge: Cambridge University Press.

Read, D. \& S.E. van der Leeuw, 2008. Biology is only part of the story .... Philosophical Transactions of the Royal Society B 363, 1959-68.

Renfrew, C., 1984. Approaches to Social Archaeology. Cambridge (MA): Harvard University Press.

Rice, P., 1999. On the origins of pottery. Journal of Archaeological Method and Theory 6, 1-54.

Schick, T., 1988. Cordage, basketry and fabrics, in Nahal Hemar Cave, eds. O. Bar-Yosef \& D. Alon. Jerusalem: Dept. of Antiquities \& Museums in the Ministry of Education \& Culture/Israel Exploration Society, 31-43.
Schick, T., 2010. Basketry finds from Gilgal, in Gilgal: Early Neolithic Occupations in the Lower Jordan Valley. The Excavations of Tamar Noy. ed. O. Bar-Yosef. Oxford: Oxbow Books, 245-9.

Schiffer, M.B., 1987. Formation Processes of the Archaeological Record. Albuquerque (NM): University of New Mexico Press.

Schmandt-Besserat, D., 1977. The earliest uses of clay in Syria. Expedition 19, 28-42.

Schmandt-Besserat, D., 1992. Before Writing, volume I: From Counting to Cuneiform. Austin (TX): University of Texas Press.

Smith, P.E.L., 1978. An interim report on Ganj Dareh Tepe, Iran. American Journal of Archaeology 82, 537-40.

van der Leeuw, S.E., 2008. Agency, networks, past and future, in Material Agency: Towards a Non-Anthropocentric Approach, eds. C. Knappett \& L. Malafouris. New York (NY): Springer, 217-47.

Vandiver, P.B., O. Soffer, B. Klima \& J. Svoboda, 1989. The origins of ceramic technology at Dolni-Vestonice, Czechoslovakia. Science 246, 1002-8.

Wright, K., 1991. The origins and development of ground stone assemblages in Late Pleistocene Southwest Asia. Paléorient 17, 19-45.

$\mathrm{Wu}, \mathrm{X} ., \mathrm{C}$. Zhang, P. Goldberg, et al., 2012. Early pottery at 20,000 years ago in Xianrendong Cave, China. Science 336, 1696-700.

Zeder, M.A., 2011. The origins of agriculture in the Near East. Current Anthropology 52, S221-35.

Zhang, C., 2002. The discovery of early pottery in China. Documenta Praehistorica 29, 29-35.

Zhao, Z., 2011. New archaeobotanic data for the study of the origins of agriculture in China. Current Anthropology 52, S295-S306.

Zhu, Y., 2013. The Early Neolithic in the Central Yellow River Valley, c. 7000-4000 BC, in A Companion to Chinese Archaeology. ed. A.P. Underhill. Chichester: Blackwell Publishing, 171-93.

Zhushchikhovskaya, I.S., 2005. Prehistoric Pottery-Making of the Russian Far East. (BAR International Series S1434.) Oxford: Archaeopress.

\section{Author biography}

Kevin Gibbs received a PhD from the University of Toronto. He is a Research Associate in the Archaeological Research Facility at the University of California, Berkeley. He has held postdoctoral fellowships at the University of Aberdeen and the University of Manchester. His research interests focus on the origins of Old World pottery. 